\title{
HYGROTHERMAL EFFECT ON AXIAL COMPRESSIVE PROPERTIES OF BIONIC BAMBOO ELEMENT
}

\author{
Wei $Y_{A N}^{1,2}$, Wansi Fu ${ }^{2}$, Bin $Z_{\text {HanG }}^{2}$, JiAnbo $Z_{H_{O U}}^{3,2}$ \\ 1Hengshui College of Vocational Technology, Hengshui, China \\ 2Beijing Forestry Machinery Research Institute of The State Forestry \\ and Grassland Administration, Beijing, China \\ ${ }^{3}$ Research Institute of Forestry New Technology, Chinese Academy of Forestry \\ Beijing, China \\ (Received March 20I9)
}

\begin{abstract}
Bionic bamboo element is innovative form inspired by honeycomb, and its axial compressive strength and node's contribution to strength under different environment were studied to explore the mechanical properties. Crack morphology and stress distribution were analyzed. The results indicated that, the strength of bionic bamboo element was $50.72 \mathrm{MPa}$, while the strength declined by $39.74 \%, 43.85 \%$ and $36.05 \%$ after being immersed in water for 30 days and hygrothermal pretreatment for 30 days and 15 days. Node had negative influence on strength due to fiber hydroscopic swelling and loose compared with the control samples, and lower humidity condition was beneficial to enhance the compressive strength, e.g. the strength of samples in humidity $20 \%$ condition for 30 days improved by $56.70 \%$ compared with the control group. Crack showed hierarchical damage with fibers' tear in length and fracture in lateral, stress distribution exhibited symmetry, and the maximum stress focused on the end of bionic bamboo element, and its thin wall was susceptible damaged. Bionic bamboo element retained the mechanical superiority of bamboo culm and promoted its recombination utilization.
\end{abstract}

KEYWORDS: Bionic bamboo element, hygrothermal environment, compressive strength, crack morphology, finite element method (FEM).

\section{INTRODUCTION}

Bamboo resource is abundant in China and its utilization has been alleviating wood shortage. Bamboo endows natural structures with excellent mechanical properties and is environmentfriendly material (Zheng et al. 2014, van der Lugt et al. 2006), especially that bamboo utilization in original status not only improve sits utilization ratio but also embodies the natural structure of bamboo sufficiently (Zhou et al. 2015, Zhou et al. 2016, Yan et al. 2017a b). 
Natural selection has perfected the structure and form of organisms, such as bamboo, to adapt the various environments (Yuan et al. 2017). More and more attention has been focused on mechanical research of bamboo in original status, and the utilization follows and respects the natural laws at the maximum level.

A fresh idea "bamboo recombining in original status (BROS)" has been proposed firstly by Professor Wansi Fu in 2006 (Fu and Zhou 2010a, b). The idea means that bamboo elements for recombination are processed based on a principle: natural structure of bamboo is reserved at maximum degree. The idea of BROS enriches the utilization type of bamboo and respects to nature compared with traditional bamboo products which are made of bamboo strands, bamboo strip, bamboo skin, bamboo filament and bamboo veneer.

It is a fact that honeycomb structure is typically lightweight and strength composite (Yuan et al. 2017). As one type of the BROS, bionic recombining technology of bamboo in original status which is also called multi-side bamboo recombining in original status (M-BROS) is innovative and belongs to bionic structure inspired by honeycomb (Fig. 1a).
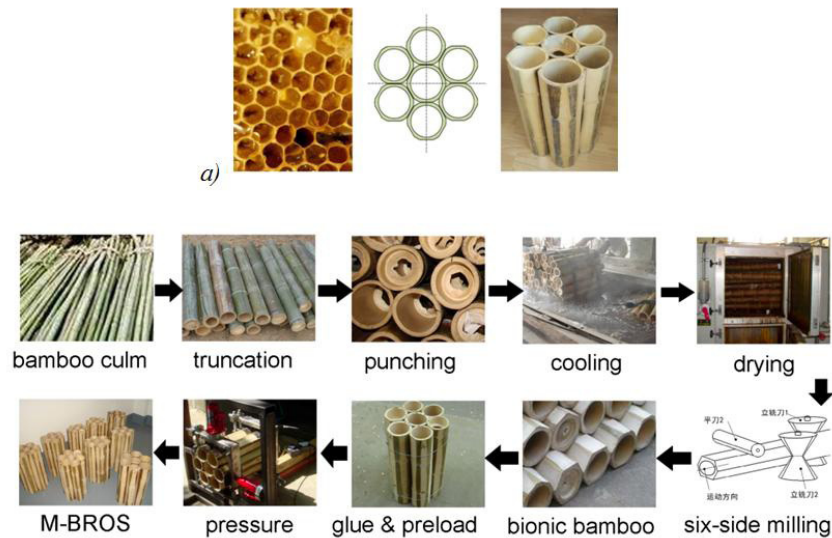

b)

Fig. 1: Basic idea (a) and process (b) of bionic bamboo recombination.

Hexagon degree has been identified due to bamboo original features and the processing characteristic, which is a ratio of the side length $\left(L_{1}\right)$ of bionic bamboo element to that $\left(L_{0}\right)$ of standard hexagon with the same diameter, that is $\mathrm{d}=L_{1} / L_{0}$, and the schematic diagram is indicated in Fig. 2. Hexagon degree with $0.6 \sim 0.8$ is appropriate for recombining based on previous test reports (Fu and Zhou 2010a).

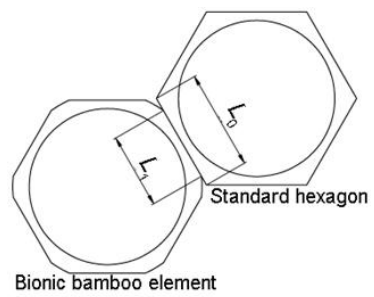

Fig. 2: Schematic diagram of hexagon degree. 
It is undoubted that bionic bamboo element is the most important constituent of the composite and has significantly impact on the whole mechanical property (Zhang et al. 2017a, b). Besides that, bamboo is biomaterial and its properties depend on environment temperature and humidity strongly. However, as a creative utilization type of bamboo in original status, mechanical characteristics of bionic bamboo element especially the characteristics under different temperature and humidity conditions are rarely conducted and reported. Mechanical test results of bionic bamboo element differ from that of traditional bamboo element, therefore, the purpose of this study was to explore the undiscovered mechanical property and its change regular of the bionic bamboo element under various environments, and this research will supply basic support for practical application of the late-model bamboo recombining material.

\section{MATERIALS AND METHODS}

Bamboo culm of Moso bamboo (Phyllostachys pubescens) which is widespread utilization was optimum to manufacture bionic bamboo element for its larger diameter class and abundant resource. Moso bamboo of 4 years age in this study was adopted from Yiyang, Hunan Province, China. The outer diameter of bamboo culm was $(101.87 \pm 2.32) \mathrm{mm}$ which is appropriate to product bionic bamboo element (Fan et al. 2012, Liu et al. 2012, 2013), and the inner diameter was $(86.07 \pm 1.84) \mathrm{mm}$.

ISO 22157-1 "Bamboo-Determination of physical and mechanical properties. Part 1 Requirements." was referred for no relevant standard about hexagon bamboo element. The test specimens with length of $100 \mathrm{~mm}$ were taken from the similar bamboo for reducing individual differences within bamboo culms. Bamboo specimens with and without node were selected to research their axial compressive properties under different conditions.

Four test conditions with different temperature, humidity and pretreated time were set based on practical nature environment in China to conduct hygrothermal pretreatment. Specimens were divided into five groups (every group had two types of samples), and marked as A, B, C, D and $\mathrm{E}$, and the number of every type in every group was no less than 10 . The details are shown in Tab.1. Test specimens of group A were immerged in water for 30 days at room temperature, test specimens of group B were placed in test box environment $\left(40^{\circ} \mathrm{C}, 90 \%\right)$ for 30 days, test specimens of group $\mathrm{C}$ were placed in test box environment $\left(40^{\circ} \mathrm{C}, 90 \%\right)$ for 15 days, while the pretreatment condition of group D was temperature $40^{\circ} \mathrm{C}$ and humidity $20 \%$ for 30 days. Group E was control.

Tab. 1: Pretreatment conditions of test specimens.

\begin{tabular}{|c|l|c|c|c|}
\hline Group & \multicolumn{1}{|c|}{ Pretreatment condition } & Temperature $\left({ }^{\circ} \mathrm{C}\right)$ & Humidity $(\%)$ & Time (days) \\
\hline A & Immerged in water & $29 \pm 1.2$ & - & 30 \\
\hline B & Hygrothermal environment & 40 & 90 & 30 \\
\hline C & Hygrothermal environment & 40 & 90 & 15 \\
\hline D & Hygrothermal environment & 40 & 20 & 30 \\
\hline E & Control (room environment) & $22 \pm 2.1$ & $52 \pm 2.3$ & - \\
\hline
\end{tabular}

\section{Mechanical test and crack observation}

Inner diameter, outer diameter and length of every test sample were measured and recorded before and after the pretreatment to calculate the deformation ratio following Eq. 1: 


$$
\alpha=\frac{l_{2}-l_{1}}{l_{1}} \times 100
$$

Where: $\alpha$ means deformation ratio of bionic bamboo element (\%); $l_{2}$ means dimension of sample after pretreatment $(\mathrm{mm}) ; l_{1}$ means dimension of sample before pretreatment $(\mathrm{mm})$.

Axial compressive test was conducted with the help of YH 229WG universal testing machine (Shanghai Yihuan Instrument Technology Co., Ltd., China) with a $200 \mathrm{kN}$ load cell capacity. Samples were put into hermetic bag after pretreatment in order to reduce the moisture content (MC) change, and the mechanical test was accomplished within 5 min.

Compressive strength in axial was calculated referring to Eqs. 2 and 3 which were based on standard hexagon model.

$$
\begin{aligned}
& \sigma=\frac{F}{S} \\
& S=\frac{3 \sqrt{3} R^{2}}{2}-\pi r^{2}
\end{aligned}
$$

Where, $\sigma$ is compressive strength ( $\mathrm{MPa})$; F means the peak load $(\mathrm{N})$; $\mathrm{S}$ means cross-section area of standard hexagon model $\left(\mathrm{mm}^{2}\right)$; R means the outer radius $(\mathrm{mm}) ; r$ means the inner radius $(\mathrm{mm})$.

Correction factor of the bionic bamboo element comparing to standard hexagon element is 0.85 (Han et al. 2014), and the value has been achieved in previous study of own team.

After mechanical test, samples with typical crack were selected to be processed appropriate size within $5 \times 5 \times 5 \mathrm{~mm}$, then the crack morphology was observed with the help of scan elastic microscope (SEM, Hitachi S-4800) after the little specimens' drying and spray-gold.

\section{Finite element method}

Axial compression of the control bionic bamboo element was emulated by ANSYS 14.0. Solid 182 was selected to establish hexagonal bamboo model which was assumed as orthogonal isotropic material (Triboulot et al. 1984, Shao 2012, Fu et al. 2013, Zhao et al. 2013, 2015).

The inner diameter, outer diameter, length and hexagon degree of the model were $90 \mathrm{~mm}$, $110 \mathrm{~mm}, 100 \mathrm{~mm}$ and 0.76 respectively. And the mechanical parameters in the three directions $\left(\mathrm{E}_{\mathrm{L}}, \mathrm{E}_{\mathrm{R}}, \mathrm{E}_{\mathrm{Z}}, \mathrm{P}_{\mathrm{RT}}, \mathrm{P}_{\mathrm{TL}}, \mathrm{P}_{\mathrm{RL}}, \mathrm{G}_{\mathrm{TL}}, \mathrm{G}_{\mathrm{RL}}\right.$ ) of Moso bamboo are shown in Tab. 2.

Tab. 2: Mechanical parameters of Moso bamboo.

\begin{tabular}{|cccccccccccc|}
\hline & \multicolumn{3}{c}{ Elasticity modulus $(\mathrm{GPa})$} & \multicolumn{3}{c|}{ Poisson's ratio ( - ) } & \multicolumn{4}{c|}{ Shear Modulus (GPa) } \\
& $\mathrm{E}_{\mathrm{L}}$ & $\mathrm{E}_{\mathrm{R}}$ & $\mathrm{E}_{\mathrm{Z}}$ & $\mathrm{P}_{\mathrm{RT}}$ & $\mathrm{P}_{\mathrm{TL}}$ & $\mathrm{P}_{\mathrm{RL}}$ & $\mathrm{G}_{\mathrm{RT}}$ & $\mathrm{G}_{\mathrm{TL}}$ & $\mathrm{G}_{\mathrm{RL}}$ \\
\hline Bamboo (Bai et al. 1999) & 10.35 & 0.50 & 0.69 & 0.308 & 0.023 & 0.019 & 0.29 & 0.90 & 0.83 \\
\hline
\end{tabular}

Subsequently, the model was meshed by free triangle, then the press strength $50.71 \mathrm{MPa}$ obtained by practical experiment was set on one end of the bionic bamboo model, while the other end was set displacement constraint. $\mathrm{X}$ and $\mathrm{Y}$ directions were radial direction of bionic bamboo element, and $\mathrm{Z}$ direction was the grain orientation, details of the model are shown in Fig. 3. Finally, results of stress and strain were achieved after solution operation and indicated by nephogram. 


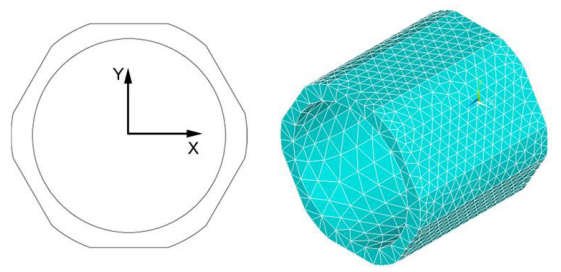

Fig. 3: Modeling of bionic bamboo element with Finite Element Method.

\section{RESULTS AND DISCUSSION}

\section{Deformation analysis}

Dry shrinkage and wet expansion characteristics are the intrinsic characteristics of bamboo for the existence of hydroxyl $(-\mathrm{OH})$ in cellulose, hemicellulose and lignin, so deformation occurs when bamboo is put in different temperature and humidity environments. Change ratio of specimen's deformation was analyzed and compared, as shown in Fig. 4.

It was found that the change ratio of outer diameter of bionic bamboo element of every pretreatment group was the maximum, followed by inner diameter, and the deformation of length was the minimum. Samples' deformation of group A was the most evident, the average change ratio of their outer diameter, inner diameter and length were $3.35 \%, 1.92 \%$ and $0.57 \%$ respectively.

The dimension turned larger when samples were put in high humidity environment, while the shrinkage occurred when samples were set in lower humidity, e.g. deformation of bionic bamboo elements in group D. It was observed that higher humidity or lower humidity means more obvious dimension deformation at the same temperature.

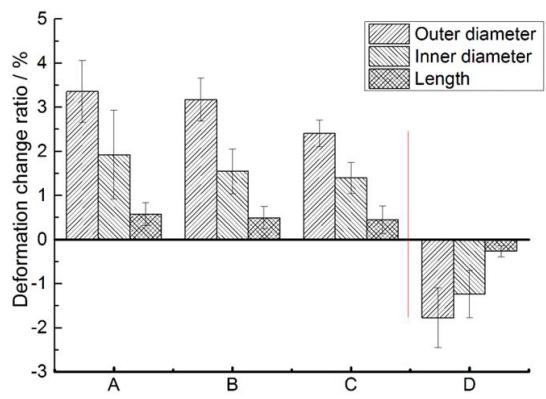

Fig. 4: Deformation change ratio of bionic bamboo element under different conditions.

\section{Node impact on compressive strength}

Node has important influence on bamboo growth and its mechanical properties (Liese 1998). It is a fact that node enhances axial compressive property of bamboo culm which is not pretreated, while no significant difference exists in bamboo culm specimens with and without node (Shao et al. 2008, Oka et al. 2014). However, it was observed that bionic bamboo element with and without node showed different characteristics after various pretreatment, and the strength comparison is indicated in Fig. 5. Compressive strength of bionic bamboo elements in control one (group E) was consistent with the predication (Shao et al. 2008, Oka et al. 2014). 
In group E, axial compressive strength of samples with node was larger than that of samples without node, and difference of compressive strength between the two types was not significant (sig. > 0.05), as shown in Tab. 3. While compressive strength of samples with and without node in group $\mathrm{C}$ and $\mathrm{D}$ showed the same regularity with the control group.

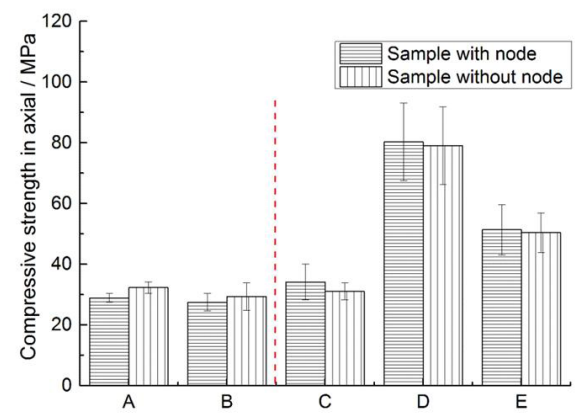

Fig. 5: Compressive strength of bionic bamboo element with and without node.

However, the mechanical property of bionic bamboo element in group A and B displayed opposite law, superior compressive property was showed by bionic bamboo element without node.

Tab. 3: Independent-sample t test of five groups.

\begin{tabular}{|c|c|c|c|c|c|c|c|c|c|c|}
\hline \multicolumn{7}{|c|}{ Levene's test for quality of variances } & \multicolumn{4}{|c|}{ T-test for equality of means } \\
\hline & \multirow{2}{*}{ F } & \multirow{2}{*}{\multicolumn{2}{|c|}{ Sig. }} & \multirow{2}{*}{$\mathbf{t}$} & \multirow{2}{*}{ df } & \multirow{2}{*}{$\begin{array}{c}\text { Sig. } \\
\text { (2-tailed) }\end{array}$} & \multirow{2}{*}{$\begin{array}{c}\text { Mean } \\
\text { difference }\end{array}$} & \multirow{2}{*}{$\begin{array}{l}\text { Stand } \\
\text { errors }\end{array}$} & \multicolumn{2}{|c|}{ 95\% Confid. interval } \\
\hline & & & & & & & & & Lower & Upper \\
\hline \multirow{2}{*}{ A } & $\begin{array}{l}\text { Equal variances } \\
\text { assumed }\end{array}$ & 0.584 & 0.467 & -3.204 & 8 & 0.013 & -4.02342 & 1.25560 & -6.91883 & -1.12800 \\
\hline & $\begin{array}{l}\text { Equal variances } \\
\text { not assumed }\end{array}$ & & & -3.204 & 7.458 & 0.014 & -4.02342 & 1.25560 & -6.95591 & -1.09093 \\
\hline \multirow{2}{*}{ B } & $\begin{array}{l}\text { Equal variances } \\
\text { assumed }\end{array}$ & 0.434 & 0.527 & -0.810 & 9 & 0.439 & -2.21936 & 2.73880 & -8.41498 & 3.97624 \\
\hline & $\begin{array}{l}\text { Equal variances } \\
\text { not assumed }\end{array}$ & & & -0.847 & 8.462 & 0.420 & -2.21936 & 2.62068 & -8.20566 & 3.76694 \\
\hline \multirow{2}{*}{$\mathrm{C}$} & $\begin{array}{l}\text { Equal variances } \\
\text { assumed }\end{array}$ & 3.419 & 0.097 & 1.161 & 9 & 0.275 & 3.64552 & 3.13973 & -3.45703 & 10.74808 \\
\hline & $\begin{array}{l}\text { Equal variances } \\
\text { not assumed }\end{array}$ & & & 1.087 & 5.425 & 0.323 & 3.64552 & 3.35300 & -4.77427 & 12.06531 \\
\hline \multirow{2}{*}{ D } & $\begin{array}{l}\text { Equal variances } \\
\text { assumed }\end{array}$ & 0.041 & 0.847 & 0.133 & 6 & 0.898 & 1.46958 & 11.02873 & -25.51675 & 28.45591 \\
\hline & $\begin{array}{l}\text { Equal variances } \\
\text { not assumed }\end{array}$ & & & 0.133 & 4.356 & 0.900 & 1.46958 & 11.01486 & -28.15246 & 31.09162 \\
\hline \multirow{2}{*}{$\mathrm{E}$} & $\begin{array}{l}\text { Equal variances } \\
\text { assumed }\end{array}$ & 3.210 & 0.111 & 0.164 & 8 & 0.974 & 1.78939 & 10.93284 & -23.42178 & 27.00055 \\
\hline & $\begin{array}{l}\text { Equal variances } \\
\text { not assumed }\end{array}$ & & & 0.200 & 5.740 & 0.848 & 1.78939 & 8.93931 & -20.32694 & 23.90572 \\
\hline
\end{tabular}


Particularly, the compressive strength of samples with and without node in group A were $37.97 \mathrm{MPa}$ and $33.94 \mathrm{MPa}$, and significant difference was indicated (sig. < 0.05). While compressive strength difference of samples with and without node in group B was not significant (sig. > 0.05). It could be deduced that pretreatment time will obviously change the mechanical property difference of bamboo with and without node by comparing pretreatment conditions of group $\mathrm{A}$ and $\mathrm{B}$, and this will provide important guidance for bamboo utilization in nature environment.

The mechanical difference between groups may be induced by the fact that fibers in vascular bundles and ground tissues in bamboo wall turned swelled and loose for absorbing water molecule in a long time (30 days). The swelling of bionic bamboo element resulted in weaker binding force between fibers, and further led to the compressive strength decline. It is a fact that vascular bundles within bamboo node are short and twisty (Liese 1998), so as to fibers' binding force of the node part dropped more easily than that of the internode.

\section{Different conditions impact on axial compression}

As biomaterial, bamboo is sensitive to environmental temperature and humidity, these results in its strength change with various environments. Compressive strength in axial of bionic bamboo element and the compressive deformation ratio after mechanical damage were calculated and analyzed, the results are displayed in Fig. 6. It was clear that the strength of groups A, B and $\mathrm{C}$ were lower than that of control samples of group $\mathrm{E}$, while the strength of group D was more excellent than that of the control one. The strength of group $\mathrm{E}$ was $50.72 \mathrm{MPa}$, and the strength of group A, B, C were $30.56 \mathrm{MPa}, 28.48 \mathrm{MPa}$ and $32.43 \mathrm{MPa}$ respectively and strength loss ratio were $39.74 \%, 43.85 \%$ and $36.05 \%$ successively, while the strength of group D was improved by $56.70 \%$ compared with the control group.

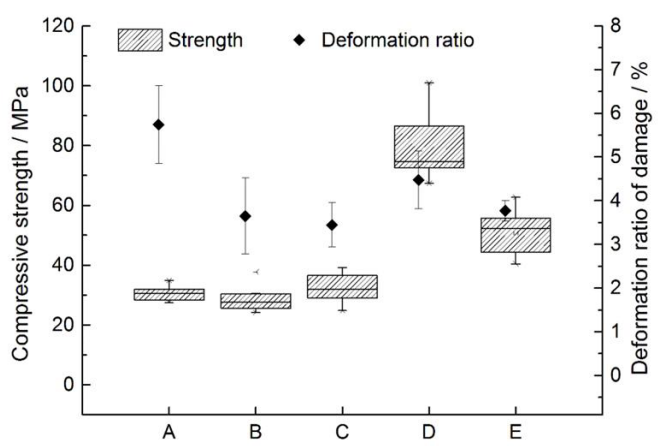

Fig. 6: Axial compressive strength of bionic bamboo element under different conditions.

It was also found that all the strength of pretreated groups taken place significant difference (sig. < 0.05) compared with the control one, as shown in Tab. 4. While the difference within groups $\mathrm{A}, \mathrm{B}$ and $\mathrm{C}$ was not significant (sig. > 0.05 ). 
Tab. 4: Significant difference analysis of compressive strength in axial of every sample.

\begin{tabular}{|c|c|c|c|c|c|c|}
\hline \multirow[b]{2}{*}{ (I) Group } & \multirow[b]{2}{*}{ (J) Group } & \multirow{2}{*}{$\begin{array}{c}\text { Mean } \\
\text { difference } \\
(\mathrm{I}-\mathrm{J})\end{array}$} & \multirow[b]{2}{*}{ Stand errors } & \multirow[b]{2}{*}{ Significant } & \multicolumn{2}{|c|}{ 95\% Confidence interval } \\
\hline & & & & & Lower & Upper \\
\hline \multirow{4}{*}{ A } & $\mathrm{B}$ & 2.08237 & 3.59770 & 0.566 & -5.1638 & 9.3285 \\
\hline & $\mathrm{C}$ & -1.87112 & 3.59770 & 0.606 & -9.1173 & 5.3750 \\
\hline & $\mathrm{D}$ & $-48.91358^{*}$ & 3.90574 & 0.000 & -56.7801 & -41.0470 \\
\hline & $\mathrm{E}$ & $-14.74908^{*}$ & 3.68237 & 0.000 & -22.1657 & -7.3324 \\
\hline \multirow{4}{*}{ B } & $\mathrm{A}$ & -2.08237 & 3.59770 & 0.566 & -9.3285 & 5.1638 \\
\hline & $\mathrm{C}$ & -3.95349 & 3.51100 & 0.266 & -11.0250 & 3.1180 \\
\hline & $\mathrm{D}$ & $-50.99595^{*}$ & 3.82602 & 0.000 & -58.7019 & -43.2899 \\
\hline & $\mathrm{E}$ & $-16.83145^{*}$ & 3.59770 & 0.000 & -24.0776 & -9.5853 \\
\hline \multirow{4}{*}{$\mathrm{C}$} & A & 1.87112 & 3.59770 & 0.606 & -5.3750 & 9.1173 \\
\hline & $\mathrm{B}$ & 3.95349 & 3.51100 & 0.266 & -3.1180 & 11.0250 \\
\hline & $\mathrm{D}$ & $-47.04246^{*}$ & 3.82602 & 0.000 & -54.7485 & -39.3365 \\
\hline & $\mathrm{E}$ & $-12.87796^{*}$ & 3.59770 & 0.001 & -20.1241 & -5.6318 \\
\hline \multirow{4}{*}{$\mathrm{D}$} & $\mathrm{A}$ & $48.91358^{*}$ & 3.90574 & 0.000 & 41.0470 & 56.7801 \\
\hline & $\mathrm{B}$ & $50.99595^{*}$ & 3.82602 & 0.000 & 43.2899 & 58.7019 \\
\hline & $\mathrm{C}$ & $47.04246^{*}$ & 3.82602 & 0.000 & 39.3365 & 54.7485 \\
\hline & $\mathrm{E}$ & $34.16450^{*}$ & 3.90574 & 0.000 & 26.2979 & 42.0311 \\
\hline \multirow{4}{*}{$\mathrm{E}$} & $\mathrm{A}$ & $14.74908^{*}$ & 3.68237 & 0.000 & 7.3324 & 22.1657 \\
\hline & $\mathrm{B}$ & $16.83145^{*}$ & 3.59770 & 0.000 & 9.5853 & 24.0776 \\
\hline & $\mathrm{C}$ & $12.87796^{*}$ & 3.59770 & 0.001 & 5.6318 & 20.1241 \\
\hline & $\mathrm{D}$ & $-34.16450^{*}$ & 3.90574 & 0.000 & -42.0311 & -26.2979 \\
\hline
\end{tabular}

Note: * difference was significant at level 0.05 .

Besides that, deformation ratio of bionic bamboo element after test had been discussed. The average ratio of group $\mathrm{E}$ was $3.77 \%$, and the value of group $\mathrm{A}$ and group $\mathrm{D}$ were larger than that of the control one, this means more toughness of the two group samples. However, the damage deformation ratio of group $\mathrm{B}$ and group $\mathrm{C}$ were smaller than that of group $\mathrm{E}$, which means the lower strength and weak deformability, this may be induced by high moisture content (MC) and mould of bamboo. It was concluded that conditions play important roles in mechanical capacity of bionic bamboo element.

\section{Crack morphology}

As we known, crack is always companied with mechanical test. It was observed that two kinds of crack were occurred in bionic bamboo element, the microscopic images are exhibited in Fig. 7. Crack was propagated along the fiber length, seriously, the fiber was fractured, as marked by arrows in Fig. 7a. While the crack in lateral was different with that, ground tissue of bamboo was fractured with flat edge, conversely, the vascular bundle damage was up faulted only with few destroyed fibers, as indicated in Fig. $7 \mathrm{~b}$.

Fracture of bamboo is failure process of intricate interplay of multiple damage modes (Shao et al. 2012), it was concluded that hierarchical structure of bamboo was beneficial to enhance its mechanical properties. 


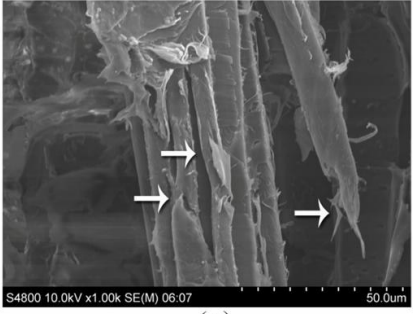

(a)

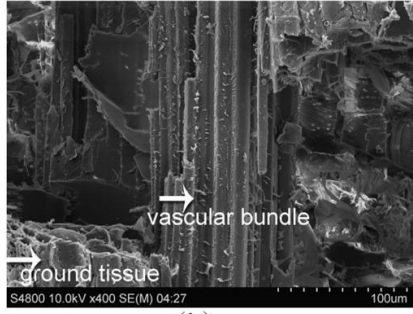

(b)

Fig. 7: Morphology of crack in grain orientation (a) and lateral direction (b).

\section{Finite element method (FEM) modelling}

Results of FEM on axial compression of bionic bamboo element are indicated by stress and strain nephogram in Fig. 8. Stress component in six directions (X, Y, Z, YZ, XZ and XY) were symmetrical distribution, and shear stress was consisted of tensile stress (positive value in nephogram) and compressive stress (negative value nephogram). Larger stress was appeared on the end of bionic bamboo element, and stretched to the middle part. The maximum stress in $\mathrm{X}, \mathrm{Y}$ and $\mathrm{Z}$ directions were 1.6 $\mathrm{MPa}, 1.9 \mathrm{MPa}$ and $55.8 \mathrm{MPa}$ respectively. Stress difference in radial and grain direction was the manifestation of bamboo anisotropy.

It was found that strain distribution was according with stress nehpogram, and exhibited symmetry. As shown in Fig. 8b, tensile and compressive strain in six directions was not uniform, and the minimum strain occurred on the thicker part of bamboo wall.

Besides that, Von Mises stress and Von Mises strain were also analyzed in this study, as shown in Fig. 9 and Fig. 10.

The Von Mises stress nephogram of bionic bamboo element in Fig. 9a indicated that the maximum stress was $53.9 \mathrm{MPa}$ which was in the end part. While bamboo culm was introduced, as shown in Fig. 9b, to compare the stress distribution with that of bionic bamboo element. Similarly, the maximum stress of bamboo culm taken place on the end part, and the value was 53.0 MPa. This indicated that no obvious difference of axial compressive strength existed between bionic bamboo element and bamboo culm, and the finding was consistent with the practical experimental results (Han et al. 2014).
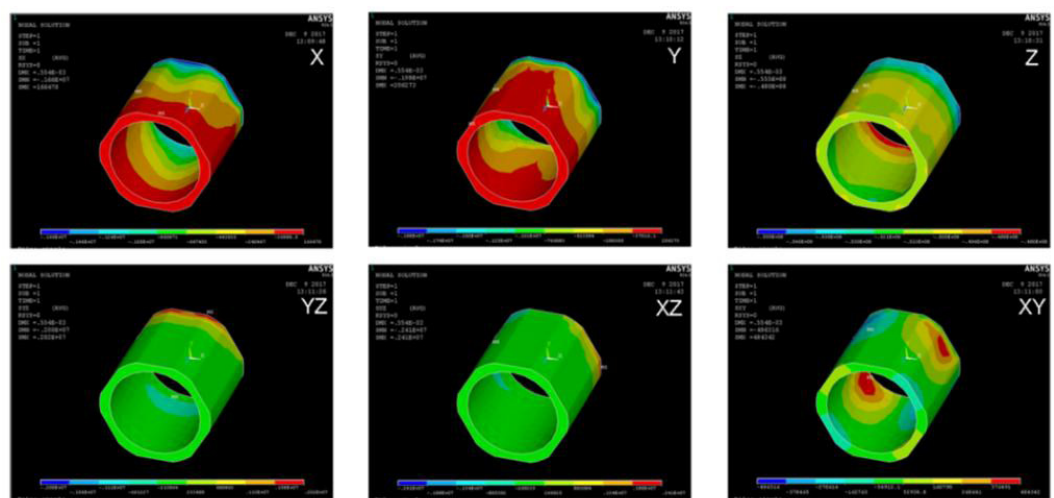

(a) 

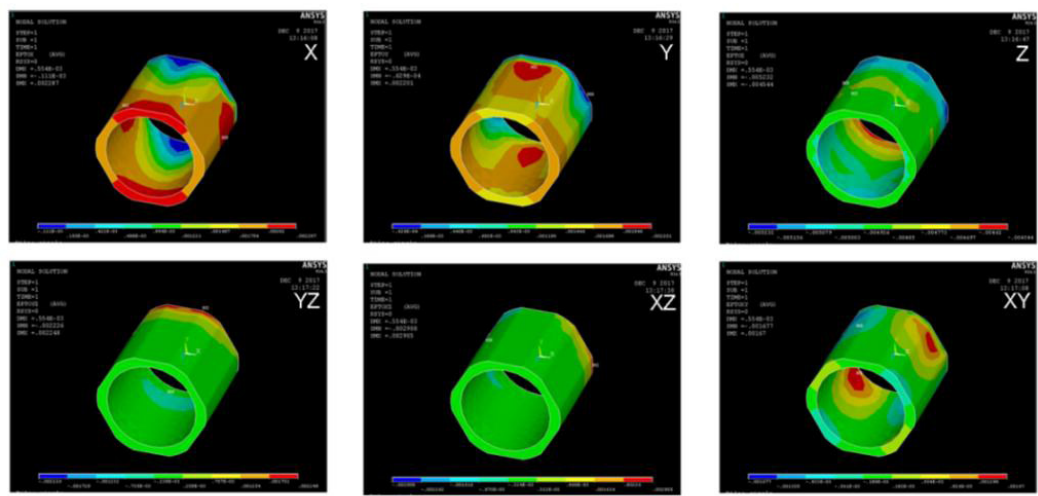

(b)

Fig. 8: Stress distribution (a) and strain distribution (b) of bionic bamboo element under axial compression.

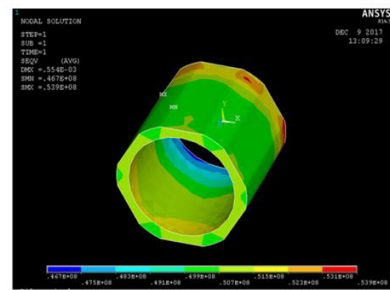

(a)

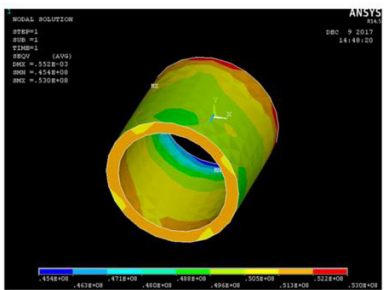

(b)

Fig. 9: Von Mises stress of bionic bamboo element (a) and bamboo culm (b).

Deformation of bionic bamboo element is shown in Fig. 10a, it was clear that length of the model was shortened and the circumferential size was expanded. The Von Mises strain comparison of bionic bamboo element (Fig. 10b) and bamboo culm (Fig. 10c) indicated that the strain in the thin wall of bionic bamboo was spread along the length direction, this phenomenon was consistent with practical compressive damage of bionic bamboo element.

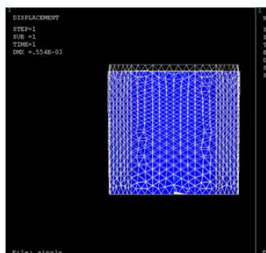

(a)

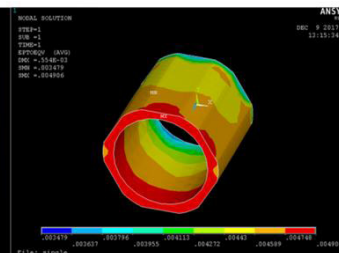

(b)

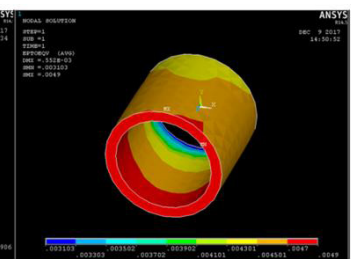

(c)

Fig. 10: Deformation and Von Mises strain of bionic bamboo element (a, b), bamboo culm (c).

The stress and strain difference of bionic bamboo element and bamboo culm showed that hexagonal bamboo technology was reasonable and meaningful. The technology is innovative and significant, and retains the mechanical superiority of bamboo culm and promoted its recombination utilization at the same time. 


\section{DISCUSSION}

Bamboo is composed of many vascular bundles embedded in ground tissue, and the arrangement of vascular bundles in internode is parallel to axis, while the arrangement is horizontal and twisty in node and its vascular bundles is smallish (Liese 1998). It could be deduced that the structure difference of internode and node is crucial reason for that bamboo specimens with node or without node show contrastive properties under high humidity conditions. It should be noted that contribution of node to compressive strength will change when its serving in different environment especially the humidity varied. This property is critical to guidance practical utilization of bamboo and ensures the security and stability of load-carrying bamboo artifacts.

It is a fact that plentiful hydroxyl $(-\mathrm{OH})$ of cellulose, hemicellulose are the main absorption points of moisture, which will lead to bamboo deformation and even fiber soften, and further reduce the resistance to compression. The founding that axial compressive strength of bionic bamboo element was declined after high humidity pretreatment is consistent with Xu's report (Xu et al. 2014). Higher moisture content of bamboo leads to greater toughness, and the strength of bamboo showed transition from rigidity to toughness by comparing the damage deformation ratio of bionic bamboo element after undergoing different pretreatment conditions. As we known, many starch granules exist in the cell lumen of bamboo (Liese 1998), and the nutriment easily leads to mildew, this may also contribute to more strength decrease under higher humidity environment. All these suggest that bamboo protection is indispensable in practical application to avoid strength decline at the most extent.

The unique structure of bamboo culm is evolved for million years natural selection and ensures the excellent mechanical properties, hierarchical structure and inherent density gradient of bamboo (Amada and Untao 2001), and it is gratifying that bionic bamboo element and its composite reserve the rare and commendable characteristics sufficiently. Strength of bionic bamboo element was almost equal to that of bamboo culm, this suggests that process technology of hexagon bamboo is successful and practical. The novel application of bamboo in original status improves the utilization ratio and processing efficiency of raw materials compared process technology of bamboo strand, bamboo strip or bamboo veneer (Fu and Zhou 2010a ). So it is not exaggerated that the bionic bamboo composite is green, economical, and energy-efficient material.

\section{CONCLUSIONS}

Compressive properties in axial of bionic bamboo element under different temperature and humidity environment were researched, and the stress and strain distribution characteristics were analyzed by Finite Element Method, the conclusions as follows:

(1) Temperature and humidity have impressive influence on the axial compressive property of bionic bamboo element, especially the strength of bionic bamboo element decrease significantly after being immersed in water and pretreated with $40^{\circ} \mathrm{C}$ and $90 \%$ for 15 days and 30 days.

(2) Node's contribution to strength varies under different conditions, strength of bionic bamboo element with node under water or high humidity environment for long time weaken obviously for the fiber loose within node. Crack mainly occurs on the thin wall with fibers' tear in length direction and fracture in horizontal direction, and shows hierarchical damage. 
(3) Stress and strain distributions of bionic bamboo element are symmetrical, and the maximum value is on the end part, this is similar with that of bamboo culm. While strain in the thin wall of bionic bamboo element is propagated along the grain direction.

(4) The hexagon pattern promotes recombination utilization of bamboo culm without destroying its natural structure, and bionic bamboo element possesses rationalization and is innovative utilization of bamboo.

\section{ACKNOWLEDGEMENTS}

The authors are grateful for the financial support from the Natural Science Foundation of China (NSFC, Grant No. 31470582). On behalf of all authors, the corresponding author states that there is no conflict of interest.

\section{REFERENCES}

1. Amada, S., Untao, S., 2001: Fracture properties of bamboo. Composites: Part B (32): 451-459.

2. Bai, X., Lee, A.W.C., Thompson, L.L., Rosowsky, D.V., 1999: Finite element analysis of Moso bamboo-reinforced Southern pine OSB composite beams. Wood and Fiber Science 31(4): 403-415.

3. Fan, L., Fu, W., Zhou, J., 2012: Research of hexagon processing technology on bamboo original multiparty recombination. Wood Processing Machinery (04): 10 and 50-52.

4. Fu, W., Zhou, J., 2010a: Preliminary study of original state polygonal recombined bamboo. China Forest Products Industry 37(3): 45-48.

5. Fu, W., Zhou, J., 2010b: Study on industrial manufacturing technology of natural arcbamboo laminated lumber. Wood Processing Machinery (06):7-11 and 15.

6. Fu, W., Zhao, Z., Han, W., Zhou, J., 2013: Research on Finite Element Model for Parallel to Bamboo Culms Axial Shear. Applied Mechanics and Materials Vol. 477-478: 986-989.

7. Han, W., Fu, W., Zhou, J., 2014: Study on mechanical properties of original state polygonal recombination bamboo unit. Wood Processing Machinery 25(03): 33-36.

8. Liese, W., 1998: The anatomy of bamboo culms. Technical Report. Int. network for bamboo and rattan. Beijing, Eindhoven, New Delhi, Pp 79, 92-94.

9. Liu, X., Fu, W., Zhao, Z., Zhou, J., 2012: The current research status and development trend of finger-jointed technology in China. Wood Processing Machinery (05): 62-67.

10. Liu, X., Fu, W., Zhao, Z., Zhou, J., Han, W., 2013: Research on the unit finger technology and mechanical properties of original state polygonal recombinant material of bamboo. Wood Processing Machinery (02): 17-20.

11. Oka, G.M., Triwiyono, A., Awaludin, A., Siswosukarto, S., 2014: Effects of node, internode and height position on the mechanical properties of Gigantochloa atroviolacea bamboo. Procedia Engineering 95: 31-37.

12. Shao, Z., 2012: Fracture mechanics of plant materials (wood, bamboo). Science Press, Beijing, Pp 4-6.

13. Shao, Z., Huang, S., Wu, F., Zhou, L., Clement, A., 2008: A study on the difference of structure and strength between internodes and nodes of Moso bamboo. Journal of Bamboo Research 27(2): 48-52. 
14. Shao, Z., Wu, Y., Wang, F., 2012: The physical model and energy absorbing mechanism of bamboo transverse fracture: the cracking of parenchyma tissue and layering of interface. Scientia Silvae Sinicae 48(7): 108-113.

15. Triboulot, P., Jodin, P., Pluvinage, G., 1984: Validity of fracture mechanics concepts applied to wood by finite element calculation. Wood Science and Technology 18(1): 51-58.

16. van der Lugt, P., van den Dobbelsteen, A.A.J.F., Janssen, J.J.A., 2006: An environmental, economic and practical assessment of bamboo as a building material for supporting structures. Construction and Building Materials 20: 648-656.

17. Xu, Q. Harries, K., Li, X., Liu, Q., Gottron, J., 2014: Mechanical properties of structural bamboo following immersion in water. Engineering Structures 81: 230-239.

18. Yan, W., Zhou, J., Zhang, B., Fu, W., Chen, Z., 2017a: Development design and mechanical properties of arc bamboo. Wood Research 62(3): 365-372.

19. Yan, W., Zhang, B., Fu, W., Zhou, J., 2017b: Strain characterization and mechanism study on annular shrinkage of bamboo culm (Phyllostachys pubescens) China Forest Products Industry 44(10): 16-20 and 26.

20. Yuan, Y., Yu, X., Yang, X., Xiao, Y., Xiang, B., Wang, Y., 2017: Bionic building energy efficiency and bionic green architecture: A review. Renewable and Sustainable Energy Reviews 74: 771-787.

21. Zhang, B., Fu, W., Zhou, J., Yan, W., 2017a: Axial compressive properties of glue-pressed engineered honeycomb bamboo(GPEHB). Wood Processing Machinery 28(2): 27-31.

22. Zhang, B., Fu, W., Zhou, J., Yan, W., Ma, C., 2017b: Effect of finger-joint position on compressive properties of glue pressed engineered honeycomb bamboo (GPEHB). Wood Processing Machinery 28(4): 29-32 and 38.

23. Zhao, Z., Fu, W., Han, W., Zhou, J., 2013: Study on bamboo culm used for structure axial compression performance numerical simulation. Advanced Materials Research 842: 13-17.

24. Zhao, Z., Yang, G., Fu, W., Chen, Z., Zhang, B., 2015: Study on bamboo culm cracking performancenumerical simulation. Wood Processing Machinery: 26 (6): 4-6.

25. Zheng, Y., Jiang, Z., Sun, Z., Ren, H., 2014: Effect of microwave-assisted curing on bamboo glue strength: Bonded by thermosetting phenolic resin. Construction and Building Materials 68: 320-325.

26. Zhou, J., Chen, L., Fu, W., Chen, Z., Zhao, Z., Cheng, W., Zhang, Z., 2016: Preparation and performance evaluation of bamboo lumber prepared by assembly and glue-curing of naturally arc-shaped segments with finger joints. Bioresources 11(1): 267-280.

27. Zhou, J., Fu, W., Qing, Y., Han, W., Zhao, Z., Zhang, B., 2015: Fabrication and performance of a glue-pressed engineered honeycomb bamboo (GPEHB) structure with finger-jointed ends as a potential substitute for wood lumber. Bioresources 10 (2): 3302-3313.

\author{
WEI YAN \\ 1'Hengshui College of Vocational Technology \\ Hengshui, Hebei Province, 053000, China \\ 2Beijing Forestry Machinery Research Institute of The State Forestry and \\ Grassland Administration \\ BEIJING, I00029 \\ China
}


Wansi Fu, Bin Zhang, Jianbo Zhou*

2Beijing Forestry Machinery Research Institute of The State Forestry and

Grassland Administration

BEIJING, IOOO29

China

JiAnBo ZHOU*

${ }^{3}$ Research Institute of Forestry New Technology, Chinese Academy of Forestry BEIJING, IOOOgI

China

*Corresponding author: zhoujianbol@126.com 